\title{
From storage to delivery: sperm volume and number of spermatozoa inside storage organs and ejaculates in males of Timogenes elegans (Scorpiones: Bothriuridae)
}

\author{
David Eduardo Vrech ${ }^{1,2,3}$, Paola Andrea Olivero ${ }^{1,2}$, Camilo Iván Mattoni ${ }^{1,2}$ and Alfredo Vicente Peretti ${ }^{1,2,3}$ : ${ }^{1}$ Universidad \\ Nacional de Córdoba, Facultad de Ciencias Exactas, Físicas y Naturales, Departamento de Diversidad Biológica y \\ Ecología, Córdoba, Argentina; E-mail: dvrech@gmail.com; ${ }^{2}$ Consejo Nacional de Investigaciones Científicas y Técnicas \\ (CONICET), Instituto de Diversidad y Ecología Animal (IDEA), Laboratorio de Biología Reproductiva y Evolución, \\ Córdoba, Argentina; ${ }^{3}$ Catedra de Diversidad Biológica II.
}

\begin{abstract}
Sperm competition influences the evolution of many reproductive traits such as gonads, sperm or genitalia. Many sperm competition analyses concentrate in testes and ejaculates. Among arachnids, scorpions constitute an intriguing taxon for examining sperm production and usage. For example, in the family Bothriuridae the females of Timogenes elegans Mello-Leitão, 1931 accept more than one male per reproductive season and males produce spermatozoa continuously, storing them inside two elastic storage organs (i.e., two seminal vesicles plus two deferent ducts) before inseminating females, using a sclerotized spermatophore. In this study, we analyzed the sperm storage organs and the ejaculate volume transferred by T. elegans. We described the volume and number of spermatozoa at storage sites and in ejaculates, and investigated ejaculate volume and concentration in remating experiences. Storage organs varied in total size. Inside the spermatophore, the volume of the sperm drop represented $38 \%$ of the volume of both sperm storage sites. The remaining space around the sperm drop is filled with a gel-like substance. The ejaculate volume and spermatozoa number did not vary significantly between consecutive matings. Timogenes elegans stored abundant sperm inside the seminal vesicles. Available sperm was divided equally between both storage organs, and ejaculates were diluted in the spermatophore, presumably, with the gel stored in the trunk. There was no effect of body condition over any of the variables analyzed. Male sperm storage and ejaculate production are discussed considering the sperm depletion hypothesis and the sperm competition theory.
\end{abstract}

Keywords: Scorpion, storage organs, ejaculates, sperm transfer, sperm numbers.

Sperm competition is an important evolutionary driver in postcopulatory sexual selection, which occurs in polyandrous species when the sperm of different males compete for the access to the ova (Parker 1970; Birkhead \& Møller 1998; Parker \& Pizzari 2010). Sperm competition influences the evolution of many morphological, physiological, and behavioral traits that are directly related to reproduction (Andersson 1994; Birkhead \& Møller 1998; Wigby \& Chapman 2004; Simmons 2014). Most studies have focused on the effect of sperm competition on testes mass, followed by the analysis of ejaculate production (Parker \& Ball 2005; Simmons 2014). Testes mass is accepted as a good proxy for sperm competition risk (Parker et al. 1997; Parker \& Ball 2005). However, the dynamics of sperm production can vary (Møller 1991; Schärer \& Vizoso 2007; Vahed \& Parker 2012) and thus sperm production is challenging to assess, mainly because the production rate of sperm is often hard to quantify (Schärer et al. 2004).

Seminal vesicles are storage organs usually found in males of many arthropods (Wedell et al. 2002). Seminal vesicles are thought to influence the outcome of sperm competition in many taxa, mainly through seminal secretions that may help, for example, sperm maintenance and viability (Ramm et al. 2005). Besides, and linked to sperm competition, it has been shown that males of species that store sperm seem to produce more sperm than species that do not store it (Orr \& Zuk 2013). The seminal secretions may be generated in an accessory gland or be a product of secretory cells in the primary reproductive system (Leopold 1976). In spiders, the seminal fluid is comprised of spermatozoa and secretions, which are produced by the somatic cells of the testis (e.g., Michalik \& Huber 2006; Michalik \& Ramirez 2014). In solpugids, the genital chamber seems to produce a secretion that is thought to be essential for sperm transfer. The deferent ducts and the glandular part of testes contribute to the secretion that helps to form the sperm droplet, similar to what happens in actinotrichid mites (Alberti \& Coons 1999; Klann 2009).

Although males can produce, maintain, and store sperm, they may become depleted of sperm at some point during the reproductive season. For example, sperm depletion may arise as a consequence of the energetic demand of generating an ejaculate (Dewsbury 1982; Rubolini et al. 2007; Parker \& Pizarri 2010). This cost is a result of spermatozoa being delivered together with accessory fluids (Dewsbury 1982). These fluids may be involved in many tasks, like maintaining spermatozoa, generating reluctance to mate with a subsequent male, (Chapman 2001; Arnqvist \& Andrés 2006), or contributing to the formation of a genital plug (Kaufman et al. 2008; Dennenmoser \& Thiel 2015).

Males may also become sperm depleted because of their inability to produce sperm continuously during adulthood (Barr 1974; Chapman 1998; Manogem 2002; Boomsma et al. 2005; Bressac et al. 2008). For example, spiders produce sperm during adulthood (Michalik \& Uhl 2005), but there are some unusual cases in which spermatogenesis ends before the final molt (Michalik et al. 2010; Michalik \& Rittschof 2011). The testes decrease in size and degenerate towards the end of adulthood. As a result, the amount of sperm available for mating is limited to the sperm inside the pedipalps, and adults lose their ability to fertilize eggs once it is used. For example, 
Schneider \& Michalik (2011) discussed the evolution of mating tactics in three species of Nephila Leach, 1815. They suggested that males that can reverse to polygamy developed the potential to economize their limited sperm supply, but they failed to produce sperm as adults. In other arachnids, such as solpugids, it has been suggested that spermatogenesis is completed after reaching adulthood (Klann et al. 2005). In this scenario, males should allocate sperm strategically over successive matings because it is a limited resource (Simmons 2014).

Among arachnids, scorpions constitute an intriguing taxon for analyzing sperm production. Males produce sperm continuously in paired testes (Jespersen \& Hartwick 1973; Alberti 1983; Michalik \& Mercati 2010; Vrech et al. 2014) and store it in two seminal vesicles (Polis \& Sissom 1990; Peretti \& Battán-Horenstein 2003; Vrech 2013). Males of some species may produce seminal secretions that are transferred to the female during mating (Peretti \& Battán-Horenstein 2003). In some species, the cylindrical gland may secrete substances that can contribute to the formation of a genital plug inside the genital atrium of inseminated females (Vachon 1953; Hjelle 1990; Peretti 2010). Sperm is transferred indirectly inside a sclerotized spermatophore deposited on the ground (Francke 1979; Hjelle 1990; Peretti 2010).

In the family Bothriuridae, Timogenes elegans Mello-Leitão, 1931 is in many aspects an exciting species for analyzing sperm production. Firstly, each female copulates with more than one male per reproductive season (Peretti 1993; Vrech et al. 2011). At the same time, males can accept more than one female during the entire reproductive season (Peretti 2003). Secondly, males produce sperm continuously in their paired testes and store them in two elastic storage organs (i.e., two seminal vesicles plus two deferent ducts) (Peretti \& Battán-Horenstein 2003). However, contrary to the situation in other bothriurid species, T. elegans males lack accessory glands inside their genital system, and there is no production of a visible genital plug (Peretti \& Battán-Horenstein 2003). Finally, T. elegans is a suitable model species, as individuals show a considerable body size, respond adequately to laboratory conditions, perform complete mating sequences, and are abundant in the Chaco region of Argentina (Acosta 1995; OjangurenAffilastro 2005).

Data on T. elegans suggest that males show relatively small testes mass compared to other closely related species (Vrech et al. 2014). So far, studies on T. elegans have only focused on the description of the reproductive system (Peretti \& BattánHorenstein 2003), sperm conjugation and its morphology (Vrech et al. 2011), as well as on the effects of polyandry on testes mass (Vrech et al. 2014). However, the volume of the storage organs and ejaculates, their concentration, and the dynamics of sperm production in light of consecutive mating events have never been evaluated.

In this study we (1) analyze the volume of the seminal vesicles and calculated the number of spermatozoa inside them; (2) measure the volume and number of spermatozoa of the male's ejaculate and (3) present data on ejaculate volume and sperm numbers in subsequent multiple matings. We hypothesize that (1) sperm production will be abundant since males of T. elegans may be under sperm competition and will produce and store a high amount of sperm; (2) Sperm number

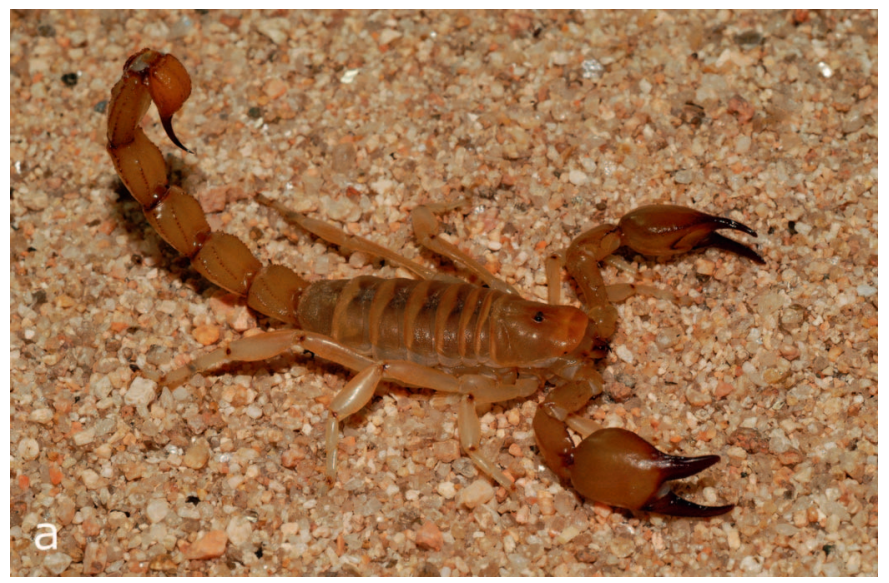

Figure 1a.-Adult male of Timogenes elegans.

will not vary from storage organs to ejaculates, as this species lacks accessory glands that may produce diluents; (3) Sperm volume will not decrease in successive multiple matings due to continuous sperm production, and may in fact increase due to sperm competition (Parker \& Pizzari 2010).

\section{METHODS}

Specimen sampling and rearing.- Adult males $(n=20)$ and females $(n=10)$ of $T$. elegans (Fig. 1a) were collected during the night using ultraviolet lamps in the Parque Provincial and Reserva Forestal Chancaní ( $31^{\circ} 22^{\prime} 13.21^{\prime \prime} \mathrm{S}, 65^{\circ} 27^{\prime} 13.75^{\prime \prime} \mathrm{W}$, Córdoba, Argentina) in January 2011. Captured individuals were kept in cylindrical plastic vials $(8 \mathrm{~cm}$ height $\times 10 \mathrm{~cm}$ diameter) with sand as the substrate and moistened cotton as a water supply. Specimen were fed on a 15-day basis with larvae of Tenebrio sp. (Insecta, Coleoptera). Voucher specimens are deposited in the scorpion collection of the Laboratorio de Biología Reproductiva y Evolución of the Universidad Nacional de Córdoba (IDEA, UNC-CONICET; curated by C. I. Mattoni).

Sperm storage organs and ejaculates.-Adult males were dissected dorsally, and the paraxial organs were removed $(n=$ 20). Then, both testes were cut at the base of the deferent duct (Fig. 2a). The dissection at this level avoided massive sperm loss (Vrech, pers. obs.). The volumes of the deferent ducts were negligible, mainly due to their small magnitude. Therefore, we focused only on seminal vesicles (Fig. 2a). Finally, right and left storage organs were isolated from their respective paraxial organ.

For the volume of sperm inside the storage organ, we took pictures of the seminal vesicles contained in the paraxial organs (Fig. 2a). The length and width of these vesicles were measured, and we used the volume of a cylinder as a proxy to the total volume of the seminal vesicle. The formula used was $\mathrm{V}=\pi \mathrm{r}^{2} \mathrm{~h}$. The radius ( $\mathrm{r}$ ) was an average obtained by measuring the diameter of the seminal vesicle at three places along the entire seminal vesicle length (h). We then divided the mean diameter by two to get the average radius of the structure. All measurements were taken three times by the same person for consistency. After calculating the volume of each vesicle, we evaluated the difference in volume between them with a Wilcoxon signed-rank test. We used the 


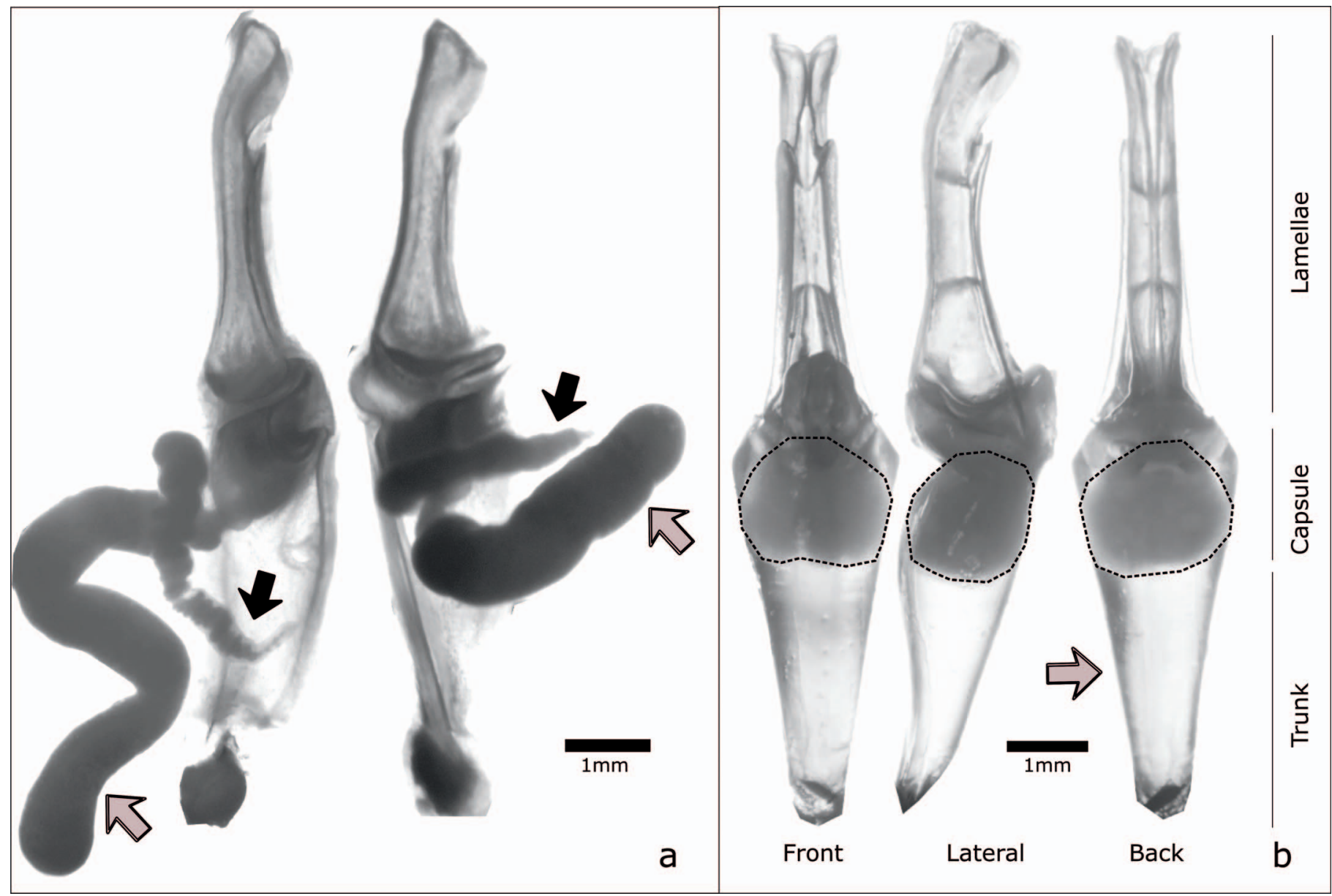

Figure 2.- Seminal vesicles and ejaculates in males from $T$. elegans. (a) Two left paraxial organs from two different males of $T$. elegans. Seminal vesicles (gray arrows). Notice that both vesicles are full of sperm. The small pouches (black arrows) are the vas deferens and correspond to the connections between seminal vesicles and testes. (b) Pre-insemination spermatophore of T. elegans in three different views. Three zones can be observed: the lamella, the capsule, containing the ejaculate (dotted polygon), and the trunk, filled with a transparent gel-like substance (gray arrow).

wilcox.test function of the package stats in $\mathrm{R}$ ( $\mathrm{R}$ Core Team 2016).

For measuring ejaculates, spermatophores were obtained in laboratory matings $(n=16)$ performed in a mating arena (18 $\mathrm{cm} \times 30 \mathrm{~cm}$ with $30 \mathrm{~cm}$ height) with sand as the substrate with bark and stones to resemble the natural habitat (Maury 1982). For acclimation, the female was placed in the arena one hour before starting the trial. The mating trial started when we placed the male in the test arena and was stopped after spermatophore deposition on the substrate, but right before sperm transfer. After each mating trial, the arena was washed with ethanol $70 \%$, and the substrate was changed. Each spermatophore was removed from the soil, photographed, and manually deployed over a slide, obtaining the entire ejaculate content. We measured the volume of the sperm drop inside the spermatophore (Fig. 2b) and after extraction (ejaculate) (Fig. 3a) to see if the volume is modified with spermatophore deployment. To estimate the volume of the sperm drop inside the spermatophore, we used the volume of a sphere $(V=4 / 3 \pi$ $\left.r^{3}\right)$. The radius ( $r$ ) was obtained dividing the diameter of the sperm drop by two in a picture of the frontal view of the spermatophore. All measurements were taken three times by the same person for consistency.

To estimate the volume of the ejaculate, we adapted a technique based on Gage (1994). We used two microscope slides separated by the height of a single coverslip (Fig. 3b). Coverslips were put on each side of the sperm storage organs or the ejaculate to avoid collapsing. After deposition, a second slide was placed over the coverslips resulting in a controlled crush of the sample. The pressure on the slides was uniform due to the use of four binder clips, each placed in a corner. The space between the coverslips was controlled on each analysis by measuring three sites along the length of the slide. The space remained uniform in all measurements $(0.1729 \pm 0.0054, n=48$; i.e., 16 spermatophores, three measurements each). The pressure of crushing scattered sperm homogeneously within an area $\left(\mathrm{mm}^{2}\right)$. We measured this area with the Image $\mathbf{J} 64$ bits image-processing software (Schindelin et al. 2015). The volume $\left(\mathrm{mm}^{3}\right)$ was obtained by multiplying the measured area by the height left between the coverslips. All volumes obtained in $\mathrm{mm}^{3}$ were converted to $\mathrm{ml}\left(1 \mathrm{~mm}^{3}=0.001 \mathrm{ml}\right)$. 


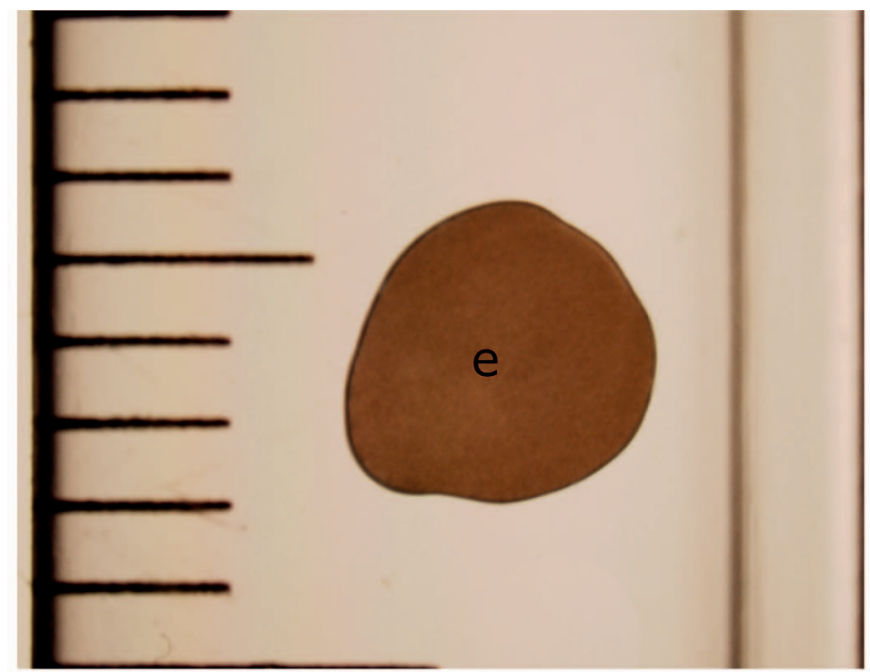

a

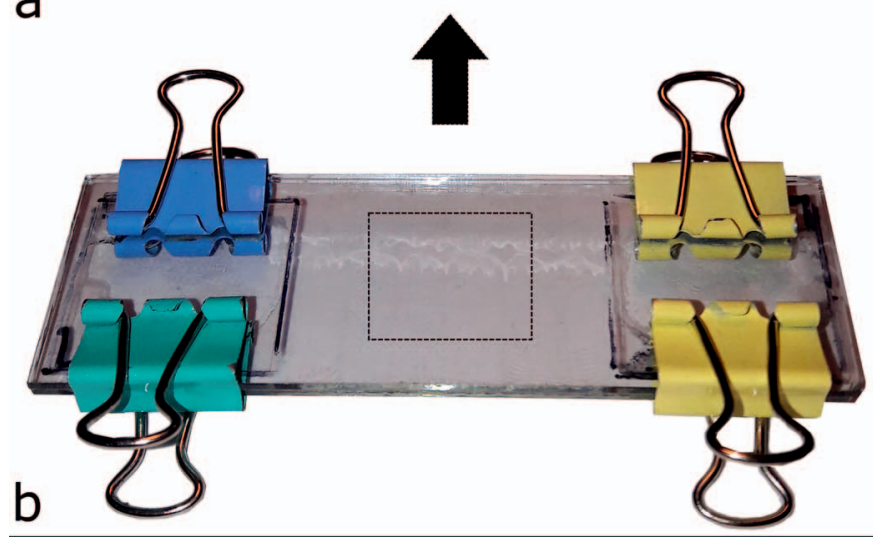

Figure 3.-Ejaculate and device used for measuring its volume. (a) Sperm drop from a manually deployed spermatophore (ejaculate). This ejaculate lays between two microscope slides. (b) Device used to measure the volume of the sperm drop. The zone occupied by the coverslips is delineated with a black marker and is pressed with binder clips. The dotted square represents the area shown in Figure 3a. Abbreviation: e: ejaculate.

Spermatozoa number: Fresh storage organs were immersed in saline solution $\left(\mathrm{NaCl}_{2} 0.9 \mathrm{gm} / 100 \mathrm{ml}\right.$ distilled water) and cut to liberate sperm packages. Sperm packages were collected using a $10 \mu \mathrm{l}$ micropipette with $1 \mu \mathrm{l}$ gradations (Finnpipette, Thermo Scientific) and mixed with $100 \mu \mathrm{l}$ of saline solution. Spermatozoa were released from sperm packages after 5 minutes of vortexing. Spermatozoa were counted using a Neubauer counting chamber, following the basic protocol for counting cells (Bukowski \& Christenson 1997; Bastidas 2014). Spermatozoa were counted in the four big squares at the corners of the chamber's grid. Additionally, the variation coefficient was used to evaluate the changeability in sperm supply in the storage organs as well as in the ejaculate. To compare the spermatozoa numbers of storage sites and the ejaculate, a Negative Binomial Generalized Linear Model test was performed using the MASS package (Venables \& Ripley 2002) in R ( R Core Team 2016).

Male body weight: Variables of storage organs, ejaculate volume, and sperm counts were regressed against body weight
Table 1.-Absolute values of the volume of seminal vesicles, sperm drop (drop contained inside the spermatophore), ejaculate (sperm drop that came out of the spermatophore) and full spermatophore volume expressed in $\mathrm{ml}$. Here, values are shown as the sum of both seminal vesicles. Spermatophore relates to the total volume that a spermatophore can contain. Values are given as mean $\pm \mathrm{SD}$. cv: coefficient of variation

\begin{tabular}{lcccc}
\hline & $\begin{array}{c}\text { Vesicles } \\
\left(\mathrm{x} 10^{3} \mathrm{ml}\right)\end{array}$ & $\begin{array}{c}\text { Sperm drop } \\
\left(\mathrm{x} 10^{3} \mathrm{ml}\right)\end{array}$ & $\begin{array}{c}\text { Ejaculate } \\
\left(\mathrm{x} 10^{3} \mathrm{ml}\right)\end{array}$ & $\begin{array}{c}\text { Spermatophore } \\
\left(\mathrm{x} 10^{3} \mathrm{ml}\right)\end{array}$ \\
\hline $\begin{array}{l}\text { Mean } \\
\text { cv }\end{array}$ & $\begin{array}{c}9.54 \pm 3.35 \\
35 \%\end{array}$ & $\begin{array}{c}2.35 \pm 0.99 \\
42 \%\end{array}$ & $\begin{array}{c}2.04 \pm 0.74 \\
36 \%\end{array}$ & $\begin{array}{c}6.23 \pm 1.03 \\
17 \%\end{array}$ \\
\hline
\end{tabular}

to analyze the possible influence of an energy trade-off in sperm production $(n=13)$. Data were modeled using GLM function from the stats package in R. For each variable, the distribution was assessed graphically with a Cullen and Frey graph in $\mathrm{R}$ using the descdist function from the fitdistrplus package (skewness-kurtosis plot) (Delignette-Muller \& Dutang 2015), and statistically with a chi-square test. We used a gamma distribution for vesicle volume, gaussian for ejaculate volume, and negative binomial for counts of spermatozoa in the seminal vesicles and ejaculates. We used the package glmmADMB for $\mathrm{R}$ (Bolker et al. 2012).

Sperm volume and number over two consecutive matings: Adult males were captured in January 2011 and $2012(n=10)$. Mating trials were scheduled weekly during the mating season (January-February) to obtain more than one spermatophore per male. The volume of the sperm drop inside the spermatophore and number of spermatozoa were measured on each of the spermatophores produced by the males following the techniques described in the previous section. A generalized linear mixed model approach with the packages Ime4 (Bates et al. 2014) and $\operatorname{glmm} A D M B$ was used to evaluate differences between successive matings. The volume and number of sperm were the response variables, and mating (first or second) was the fixed factor. We used the identity of the male as a random factor, and in both models the variance of the random effect was negligible.

\section{RESULTS}

Sperm volume in storage organs and spermatophore.- In the storage organs, the seminal vesicle was always filled with sperm (Fig. 2a). The deferent ducts were usually less fully filled (black arrows in Fig. 2a). The volumes of the seminal vesicles showed a coefficient of variation of 35\% among males (Table 1). Both seminal vesicles (right and left) had similar volumes (Wilcoxon rank paired test; $\mathrm{V}=76, P=0.38$ ). Seminal vesicles stored 4.67 times the volume of the ejaculate delivered inside the spermatophore (see Table 1).

Sperm inside the spermatophore (sperm drop) did not differ with the ejaculate that was extruded from the spermatophore (Wilcoxon rank paired test; $\mathrm{V}=71, P=0.90)$ (Table 1). The sperm drop inside the spermatophore represented a part (38\%) of the total volume of the spermatophore (Fig. 2b). The total volume of the available storage place within the spermatophore was larger than the volume of the sperm drop and the ejaculate (Table 1). This remaining space inside the spermatophore was filled with a gel-like substance, mainly located at the 
Table 2.- Volume and numbers of spermatozoa inside spermatophores deposited in two consecutive mating events.

\begin{tabular}{ccc}
\hline Matings & $\begin{array}{c}\text { Ejaculate volume } \\
\left(\mathrm{x} 10^{3} \mathrm{ml}\right)\end{array}$ & $\begin{array}{c}\text { Spermatozoa number } \\
\left(\times 10^{10}\right)\end{array}$ \\
\hline $\begin{array}{c}\text { Male } 01 \\
1\end{array}$ & 2.58 & 0.56 \\
2 & 2.44 & 0.23 \\
Male 05 & & \\
1 & 2.41 & 1.84 \\
2 & 3.56 & 3.25 \\
Male 06 & & \\
1 & 2.29 & 1.03 \\
2 & 2.40 & 2.89 \\
Male 09 & & \\
1 & 3.13 & 0.17 \\
2 & 3.14 & 0.05 \\
\hline
\end{tabular}

bottom of the capsule, filling the trunk, around the sperm drop (Fig. 2b, grey arrow). The ejaculate consisted of the sperm drop inside the spermatophore and part of the gel-like substance, which comes out with sperm after spermatophore activation.

Male body weight did not correlate with the volume of the storage organs $(\mathrm{GLM} \mathrm{z}=1.35 ; P=0.18)$. There was a positive influence of male body weight on the ejaculate volume (GLM $\mathrm{z}=2.89 ; P=0.0039$ ).

Sperm counts inside storage organs and spermatophores. Inside the seminal vesicle, sperm number was $1.32 \pm 9.41 \times$ $10^{11}$, and inside the spermatophore $1.67 \pm 1.13 \times 10^{10}$ spermatozoa. The coefficient of variation of spermatozoa numbers was 0.71 and 0.67 respectively, and there was a difference between both counts (Negative Binomial GLM, z = 7.151, $\left.P=8.59 \times 10^{-13}\right)$. The number of spermatozoa contained inside the spermatophore represented $13 \%$ of the spermatozoa stored inside both storage organs.

Male body weight did not influence sperm number within the storage organs or ejaculates (GLM sperm count in storage organs, $\mathrm{z}=-0.05, P=0.96$; GLM sperm count in ejaculates, $\mathrm{z}$ $=0.57, P=0.57$ ).

Volume and sperm number of successive matings.-Four males mated a second time (Table 2). The rest of the males did not remate $(n=6)$. Ejaculate volume, and spermatozoa numbers did not vary significantly between successive matings (GLMM (ejaculate volume) $\mathrm{z}=1.15, P=0.25$; (spermatozoa numbers) $\mathrm{z}=0.76, P=0.44)$.

\section{DISCUSSION}

The present study focused on sperm storage and ejaculate production in the male of the neotropical scorpion $T$. elegans. By measuring the total volume and number of spermatozoa, we could gather information about the pattern of sperm production in this species. The sperm volume inside the seminal vesicles (storage organs) was higher than inside the spermatophore. The ejaculate showed a decrease in the number of spermatozoa inside the spermatophore compared to the seminal vesicles. In contrast, the analysis of successive matings revealed that ejaculate size was maintained and did not change substantially in volume and sperm number, at least in two spermatophore depositions. Additionally, we found that the body weight influenced the ejaculate volume positively but did not affect the other variables analyzed.

Sperm storage organs and ejaculates.-The size of the storage organs limits the amount of sperm available for each spermatophore production. In $T$. elegans, storage organs are full and vary in size between males (this was also seen when analyzing the coefficient of variation). At first glance, in $T$. elegans, each storage organ could store the equivalent volume of at least four ejaculates. However, since spermatozoa were more diluted in the ejaculate, storage organs may store more, and the total potential ejaculates that storage organs can produce might be higher.

As expected, sperm drop volumes inside the spermatophore and ejaculate volume are equivalent. Inside the spermatophore, sperm seems to be already mixed with the gel-like substance before coming out. This fact could explain the similarity in the volume of the sperm drop inside the spermatophore and the ejaculate. The rest of the gel-like substance that remains might help to extrude the ejaculate (Francke 1979). Besides, this gel-like substance may have other functions, similar to those of seminal fluids in other arthropods (Svärd \& Wiklund 1989). Sperm numbers decreased inside the ejaculates in one order of magnitude. We did not expect a dilution inside the ejaculate, regarding the further addition of secretory products, as males of T. elegans lack accessory glands connected with the capsular region of the hemispermatophores inside the paraxial organs (Peretti \& Battán-Horenstein 2003). Nevertheless, in many taxa, seminal secretions can be generated in other parts of male's reproductive tract like testes or ejaculatory ducts (Chapman \& Davies 2004; den Boer et al. 2008; Avila et al. 2011). In fact, in spiders, seminal secretions are added to the sperm in testes and deferent ducts (Herberstein et al. 2011; Michalik \& Lipke 2013; Michalik \& Ramirez 2014). As we previously stated, the gel-like substance that fills the trunk comes out mixed with the sperm drop. Thus, the gel-like substance inside the spermatophore may serve as the diluent of the spermatozoa of the ejaculate. Still, further analysis of the secretory tissues along the distal part of the storage organs, and the detailed examination of the gel-like substance are needed. These analyses may help to reveal the formation process of the seminal fluid as well as the origin of the gel-like substance.

In our study, the male's body weight influenced the volume of the ejaculate positively, suggesting that heavier males produce ejaculates with higher volume. Using similar approaches, most studies in arthropods found that the ejaculate or spermatophore size may covary positively with body size or weight of the male (e.g., Wedell 1993; Bissoondath \& Wiklund 1996; MacDiarmid \& Butler 1999; Gosselin et al. 2003; Jivoff 2003; Rubolini et al. 2006). Our results suggest that males with higher reserves can allocate more resources to sperm production. Ejaculates are costly to produce and force the organism to be in an optimal condition having energetic reserves to compensate for the production of ejaculates (Jiménez-Pérez \& Wang 2004; Gress \& Pitnick 2017).

Sperm counts.-Here, we reported a sperm count on the order of $1 \times 10^{11}$ inside the storage organs and $1 \times 10^{10}$ in an ejaculate. Among arachnids, we did not find data on sperm counts inside the male's storage organs. However, there are many excellent works analyzing spermatozoa numbers of 
ejaculates. For example, in spiders, spermatozoa count from ejaculates inside the male's palps are lower than we found in the present study, ranging from $1 \times 10^{3}$ to $1 \times 10^{5}$ (Arnaud et al. 2001; Bukowski et al. 2001; Snow \& Andrade 2004; Ceballos et al. 2015). Bukowski \& Christenson (1997) also showed that sperm stored inside the female's spermatheca were on the order of $1 \times 10^{4}$. However, sperm counts in scorpions more closely resembled ejaculates of other arthropods (e.g., Brown \& Knouse 1973; Swallow \& Wilkinson 2002; Sato et al. 2006; Vahed 2006; Dallai et al. 2009; Aron et al. 2016). Similar to what happened with scorpions' seminal vesicles, Snow \& Andrade (2004) also reported a correlation between the number of spermatozoa in the right and left pedipalps. They show that both charged an equivalent number of spermatozoa, but with a few orders of magnitude lower than what we reported here for the volume of right and left storage organs.

Successive matings. - Regarding our analysis of successive matings in T. elegans, sperm depletion is not evident in the two observed consecutive matings. This result may be expected in a species that has continuous sperm production, like T. elegans. Similarly, in a study that involved a tephritid dipteran, sperm reserves did not drop over successive matings (Pérez-Staples \& Aluja 2006). In fact, sperm reserves did not become depleted even after three matings in a single day. Males partitioned their sperm production avoiding sperm depletion and maintaining sperm reserves.

Besides sperm depletion, males can allocate sperm strategically in response to sperm competition (Parker \& Pizzari 2010; Simmons 2014). Again, males from T. elegans seem not to respond to sperm competition, as ejaculate volume and sperm numbers remain unaltered in successive matings. If this is the case, we would have found different strategies and patterns of sperm allocation (Abe \& Kamimura 2015). For example, in lepidopterans, sperm number could decline over successive matings (Cook \& Gage 1995) or could increase in the second mating and finally decrease in the third (Watanabe et al. 1998).

Preliminary analyses in other Bothriuridae suggests that sperm depletion may be present in scorpions (D. Vrech et al., unpublished). Scorpions show a refractory period that lasts until both paraxial organs have regenerated their contents. Data in Bothriurus bonariensis (C.L. Koch, 1842) suggests that males need approximately five days for the regeneration plus two more days to regain receptiveness to mate (Peretti \& Acosta 1998). Males from T. elegans in the present study remated within this same period. In B. bonariensis, ejaculate depletion was observed in the course of three spermatophore depositions. However, the pattern of sperm depletion in $T$. elegans may not be equally evident after only two successive matings. Thus, in the present study, the number of achieved matings may have been insufficient to allow a conclusion about sperm depletion in this scorpion species. More data on successive spermatophore depositions, as well as precise data on the actual mating systems in the field, are subjects that should be strictly assessed in future works of scorpions.

Ejaculate dynamics.- The question that arises in T. elegans is: why do males produce such large number of spermatozoa? Indeed, the number of produced spermatozoa in animals is much higher compared to the number needed to fertilize the female's entire set of ova (Brown \& Knouse 1973; Parker 1982;
Thornhill \& Alcock 1983; Pizzari \& Parker 2009; Xu \& Wang 2010). Timogenes elegans has a male-biased sex ratio (Nime et al. 2014). Besides, females may mate with multiple males (Polis \& Sissom 1990; Peretti 2010), can store sperm inside paired spermathecae (Volschenk et al. 2008), and receive a relatively ineffective genital plug (Peretti \& Battán-Horenstein 2003; Mattoni \& Peretti 2004). These characteristics show a system with a potentially high risk of sperm competition (Parker 2000). As many other scorpions, males of T. elegans live as adults for only one mating season (Maury 1982; Peretti 1996; Polis \& Sissom 1990). Thus, the need to produce a significant number of spermatozoa would be linked to the possibility of filling many spermatophores and thus being able to inseminate many different females (Parker \& Pizzari 2010; Vahed \& Parker 2012). A high successive ejaculate investment often reduces the number of females that a male can inseminate and may reduce the male's longevity (Scharf et al. 2013). Although the spermatophore is a sclerotized structure, the volume of ejaculate may change as the variation coefficient of the ejaculate in our analysis suggests.

The dilution of sperm observed in the ejaculate of T. elegans may help to fill more spermatophores with a fixed number of spermatozoa. Following Acosta \& Maury (1990), we calculated an average of 110 days as the total effective reproductive period in T. elegans (i.e., end of November to the beginning of March). Males of this species need five days to regenerate the hemispermatophores (Peretti \& Acosta 1998), and approximately two more days to regain willingness to mate (Peretti 1993). In a maximum scenario, spermatophore production would result in approximately 16 spermatophores for the entire reproductive season (110 divided by 7 ). Our data suggest that both storage organs may store a volume close to that of five spermatophores. Sperm is continuously produced, and seminal vesicles will never be empty. Unfortunately, we do not have precise data on sperm dynamics inside the storage organs to know how many spermatophores males can produce in the entire season. Sperm measured in one sample of the two seminal vesicles was nearly $33 \%$ of the quantity found in the spermatophore contents calculated for the entire season (16 spermatophores). So, with only filling both seminal vesicles once, the males assure a third (i.e., the volume of 4.67 spermatophores) of the whole sperm production for the entire reproductive season. We should bear in mind that five spermatophores represent a great production for males, and, that this theoretical number of spermatophores may be difficult to reach in nature, as other variables may be affecting this capacity. For example, the rate of predation may vary daily (Nime et al. 2013). Besides, the operational sex ratio is thought to be biased towards males, and female availability for mating can be reduced.

There is another hypothesis that states that a male can have an increased sperm production to counter the effect of interspecific sperm competition, between two closely related species that are living in sympatry. For example, Carretero et al. (2006) and Kaliontzopoulou et al. (2007) found that sympatric males of two reptile species of Podarcis produced relatively more sperm, suggesting there may be a sexual interaction between them. Naretto et al. (2016) found something similar in male Salvator lizards, but this time testes mass was affected but sperm number was not. Although there 
are studies in arthropods about reproductive interference (e.g., Costa-Schmidt \& Machado 2012, Shuker et al. 2015), to our knowledge, there are no studies that evaluate sperm production between similar species. Timogenes elegans may live in sympatry with one sister species, $T$. dorbignyi (GuérinMéneville, 1843). In this scenario, both species could incur in interspecific sperm competition. However, this may rarely be the case. Timogenes dorbignyi is substantially smaller than T. elegans (Ojanguren-Affilastro 2005) and heterospecific mating trials rarely result in courtship (Peretti 2003; Vrech pers. obs.). Besides, the level of mating synchrony is apparently low (C. Mattoni, A. Peretti pers. obs.). Finally, courtship displays are different between them (Peretti 2003).

We could confirm some of our hypotheses. Males from $T$. elegans show a high and continuous sperm production. Sperm is divided equally between both storage organs. Contrary to our presumptions, the data showed that the ejaculates became diluted when passing to the spermatophore. Secretory tissue throughout the reproductive system, as well as the gel-like substance, may be candidates for aiding to dilute sperm. We should not discard the presence of secretory tissues in some other part of the reproductive system. We do not know the location and mechanism as accessory glands are not present. Future studies may answer if the gel-like substance inside the trunk acts as the diluent. Successive matings did not suggest sperm depletion. However, investigations of ejaculate dynamics in more scorpions and other arachnids are still lacking. For this reason, further studies in other species of Bothriuridae and other families would be beneficial to offer a comparative survey of sperm production across the entire order.

\section{ACKNOWLEDGMENTS}

We thank Matias Izquierdo, Lucia Calbacho-Rosa, Fedra Bollatti, Silvana Burela and Monica Nime for their help during field samplings. We also thank Martín Ramírez, Margarita Chiraraviglio, Alejandro Guidobaldi, Peter Michalik and two anonymous reviewers for critics and suggestions that contributed to improve previous versions of the manuscript. We are also very thankful with Germán Gonzalez with his help on statistical modeling, and with David Lee who helped improve the language. Finally, we acknowledge funding by CONICET, Foncyt, and Secyt-UNC.

\section{LITERATURE CITED}

Abe, J. \& Y. Kamimura. 2015. Sperm economy between female mating frequency and male ejaculate allocation. American Naturalist 185:406-416.

Acosta, L.E. 1995. The scorpions of the Argentinian western Chaco. I. Diversity and distributional patterns. Biogeographica 71:49-59.

Acosta, L.E. \& E.A. Maury. 1990. Estridulación en Timogenes elegans. Boletín de La Sociedad Biológica de Concepción, Chile 61:29-37.

Alberti, G. 1983. Fine structure of scorpion spermatozoa. Journal of Morphology 212:205-212.

Alberti, G. \& L.B. Coons. 1999. Acari: mites. Microscopic anatomy of invertebrates 8:515-1265.

Andersson, M.B. 1994. Sexual Selection. Princeton University Press.

Arnaud, L., E. Haubruge \& M.J.G. Gage. 2001. Sperm size and number variation in the red flour beetle. Zoological Journal of the Linnean Society 133:369-375.
Arnqvist G. \& J.A. Andrés. 2006. The effects of experimentally induced polyandry on female reproduction in a monandrous mating system. Ethology 112:748-756.

Aron, S., P. Lybaert, C. Baudoux, M. Vandervelden \& D. Fournier. 2016. Sperm production characteristics vary with level of sperm competition in Cataglyphis desert ants. Functional Ecology 30:614-624.

Avila, F.W., L.K. Sirot, B.A. Laflamme, C.D. Rubinstein \& M.F. Wolfner. 2011. Insect seminal fluid proteins: identification and function. Annual Review of Entomology 56:21-40.

Barr, A.R. 1974. Symposium on reproduction of arthropods of medical and veterinary importance: V. Reproduction in Diptera of medical importance with special reference to mosquitoes. Journal of Medical Entomology 11:35-40.

Bastidas, O. 2014. Cell counting with Neubauer Chamber. Technical note. Online at http://www.celeromics.com/en/resources/docs/ Articles/Cell-counting-Neubauer-chamber.pdf

Bates, D., M. Maechler, B. Bolker \& S. Walker. 2014. lme4: Linear mixed-effects models using Eigen and S4. R package version 1(7): $1-23$.

Birkhead, T.R. \& A.P. Møller. 1998. Sperm Competition and Sexual Selection. Academic Press, Massachusetts.

Bissoondath, C.J. \& C. Wiklund. 1996. Effect of male mating history and body size on ejaculate size and quality in two polyandrous butterflies, Pieris napi and Pieris rapae (Lepidoptera: Pieridae). Functional Ecology 10:457-464.

Bolker, B., H. Skaug, A. Magnusson \& A. Nielsen. 2012. Getting started with the glmmADMB package. Available at glmmadmb. rforge. r-project. org/glmmADMB. pdf.

Boomsma, J.J., B. Baer \& J. Heinze. 2005. The evolution of male traits in social insects. Annual Review of Entomology 50:395-420.

Bressac C., D. Damiens \& C. Chevrier. 2008. Sperm stock and mating of males in a parasitoid wasp. Journal of Experimental Zoology part B-Molecular and Developmental Evolution 310b:160-166.

Brown, G.G. \& J.R. Knouse. 1973. Effects of sperm concentration, sperm aging, and other variables on fertilization in the horse-shoe crab, Limulus polyphemus L. Biological Bulletin 144:462-470.

Bukowski, T.C. \& T.E. Christenson. 1997. Determinants of sperm release and storage in a spiny orbweaving spider. Animal Behaviour 53:381-395.

Bukowski, T.C., C.D. Linn \& T.E. Christenson. 2001. Copulation and sperm release in Gasteracantha cancriformis (Araneae: Araneidae): differential male behaviour based on female mating history. Animal Behaviour 62:887-895.

Carretero, M.A., R. Ribeiro, D. Barbosa, P. Sá-Sousa \& D.J. Harris. 2006. Spermatogenesis in two iberian Podarcis lizards: relationships with male traits. Animal Biology 56:1-12.

Ceballos, L., T.M. Jones \& M.A. Elgar. 2015. Patterns of sperm transfer in the golden orb-weaver Nephila edulis. Ethology 121:617-624.

Chapman, R.F. 1998. The Insects: Structure and Function. Cambridge University Press.

Chapman, T. 2001. Seminal fluid-mediated fitness traits in Drosophila. Heredity 87:511-521.

Chapman, T. \& S.J. Davies. 2004. Functions and analysis of the seminal fluid proteins of male Drosophila melanogaster fruit flies. Peptides 25:1477-1490.

Cook, P.A. \& M.J.G. Gage. 1995. Effects of risks of sperm competition on the numbers of eupyrene and apyrene sperm ejaculated by the moth Plodia interpunctella (Lepidoptera: Pyralidae). Behavioral Ecology and Sociobiology 36:261-268.

Costa-Schmidt, L.E. \& G. Machado. 2012. Reproductive interference between two sibling species of gift-giving spiders. Animal Behaviour 84:1201-1211.

Dallai, R., Z.V. Zizzari \& P.P. Fanciulli. 2009. Different sperm number in the spermatophores of Orchesella villosa (Geoffroy) 
(Entomobryidae) and Allacma fusca (L.) (Sminthuridae). Arthropod Structure and Development 38:227-234.

Delignette-Muller, M.L. \& C. Dutang. 2015. fitdistrplus: An R package for fitting distributions. Journal of Statistical Software 64(4): $1-34$

den Boer, S.P.A., J.J. Boomsma \& B. Baer. 2008. Seminal fluid enhances sperm viability in the leafcutter ant Atta colombica. Behavioral Ecology and Sociobiology 62:1843-1849.

Dennenmoser, S. \& M. Thiel. 2015. Cryptic female choice in crustaceans. Pp. 203-237. In Cryptic Female Choice in Arthropods (A.V. Peretti \& A Aisenberg, eds.). Springer International Publishing, Switzerland.

Dewsbury, D.A. 1982. Ejaculate cost and male choice. American Naturalist 119:601-610.

Francke, O.F. 1979. Spermatophores of some north American scorpions (Arachnida, Scorpiones). Journal of Arachnology 7:1932.

Gage, M.J.G. 1994. Associations between body size, mating pattern, testis size and sperm lengths across butterflies. Proceedings of the Royal Society of London. Series B: Biological Sciences 258:247254

Gosselin, T., B. Sainte-Marie \& L. Bernatchez. 2003. Patterns of sexual cohabitation and female ejaculate storage in the American lobster (Homarus americanus). Behavioral Ecology and Sociobiology $55: 151-160$.

Gress, B.E. \& S. Pitnick. 2017. Size-dependent ejaculation strategies and reproductive success in the yellow dung fly, Scathophaga stercoraria. Animal Behaviour 127:281-287.

Herberstein, M.E., J.M. Schneider, G. Uhl \& P. Michalik. 2011. Sperm dynamics in spiders. Behavioral Ecology 22:692-695.

Hjelle, J.T. 1990. Anatomy and morphology. Pp. 9-63. In The Biology of Scorpions (G.A. Polis, ed.). Stanford University Press, Stanford.

Jespersen, ̊. \& R. Hartwick. 1973. Fine structure of spermiogenesis in scorpions from the family Vejovidae. Journal of Ultrastructure Research 45:366-383.

Jiménez-Pérez, A. \& Q. Wang. 2004. Effect of body weight on reproductive performance in Cnephasia jactatana (Lepidoptera: Tortricidae). Journal of Insect Behavior 17:511-522.

Jivoff, P. 2003. A review of male mating success in the blue crab, Callinectes sapidus, in reference to the potential for fisheriesinduced sperm limitation. Bulletin of Marine Science 72:273-286.

Kaliontzopoulou, A., M.A. Carretero \& G.A. Llorente. 2007. Multivariate and geometric morphometrics in the analysis of sexual dimorphism variation in Podarcis lizards. Journal of Morphology 268:152-165.

Kaufman, W.R., A.S. Bowman \& P.A. Nuttall. 2008. Factors that determine sperm precedence in ticks, spiders and insects: a comparative study. Pp. 164-185. In Ticks: Biology, Disease and Control. (A.S. Bowman \& P.A. Nuttall, eds.). Cambridge University Press, Cambridge.

Klann, A.E. 2009. Histology and ultrastructure of solifuges: Comparative studies of organ systems of solifuges (Arachnida, Solifugae) with special focus on functional analyses and phylogenetic interpretations. PhD thesis, University of Greifswald.

Klann, A.E., A.V. Peretti \& G. Alberti. 2005. Ultrastructure of male genital system and spermatozoa of a Mexican camel-spider of the Eremobates pallipes species group (Arachnida, Solifugae). Journal of Arachnology 33:613-621.

Leopold, R.A. 1976. Role of male accessory glands in insect reproduction. Annual Review of Entomology 21:199-221.

MacDiarmid, A.B. \& M.J. Butler. 1999. Sperm economy and limitation in spiny lobsters. Behavioral Ecology and Sociobiology 46:14-24.

Manogem, E.M. 2002. Dynamics of spermiogenesis in Spodoptera mauritia Boisd. (Lepidoptera: Noctuidae) Thesis. Department of Zoology, University of Calicut.

Mattoni, C.I. \& A.V. Peretti. 2004. The giant and complex genital plug of the asper group of Bothriurus (Scorpiones, Bothriuridae): morphology and comparison with other genital plugs in scorpions. Zoologischer Anzeiger 243:75-84.

Maury, E.A. 1982. El género Timogenes Simon 1880 (Scorpiones, Bothriuridae). Revista de la Sociedad Entomológica Argentina 41:23-48.

Michalik, P. \& B.A. Huber. 2006. Spermiogenesis in Psilochorus simoni (Berland, 1911) (Pholcidae, Araneae): evidence for considerable within-family variation in sperm structure and development. Zoology 109:14-25.

Michalik, P. \& D. Mercati. 2010. First investigation of the spermatozoa of a species of the superfamily Scorpionoidea (Opistophthalmus penrithorum, Scorpionidae) with a revision of the evolutionary and phylogenetic implications of sperm structures in scorpions (Chelicerata, Scorpiones). Journal of Zoological Systematics and Evolutionary Research 48:89-101.

Michalik, P. \& E. Lipke. 2013. Male reproductive system of spiders. Pp. 173-187. In Spider Ecophysiology (W. Nentwig, ed.). Springer Berlin Heidelberg.

Michalik, P. \& M.J. Ramírez. 2014. Evolutionary morphology of the male reproductive system, spermatozoa and seminal fluid of spiders (Araneae, Arachnida) - Current knowledge and future directions. Arthropod Structure \& Development 43:291 e322.

Michalik, P. \& C.C. Rittschof. 2011. A comparative analysis of the morphology and evolution of permanent sperm depletion in spiders. PLoS ONE 6(1) e16014

Michalik, P. \& G. Uhl. 2005. The male genital system of the cellar spider Pholcus phalangioides (Fuesslin, 1775) (Pholcidae, Araneae): development of spermatozoa and seminal secretion. Frontiers in Zoology 2:1-12.

Michalik, P., B. Knoflach, K. Thaler \& G. Alberti. 2010. Live for the moment adaptations in the male genital system of a sexually cannibalistic spider (Theridiidae, Araneae). Tissue and Cell 42:3236.

Møller, A.P. 1991. Sperm competition, sperm depletion, paternal care, and relative testis size in birds. American Naturalist 137:882906.

Naretto, S., C.S. Blengini, G. Cardozo \& M. Chiaraviglio. 2016. Pre and postcopulatory traits of Salvator male lizards in allopatry and sympatry. Scientifica 2016:1-9.

Nime, M.F., F. Casanoves, D.E. Vrech \& C.I. Mattoni. 2013. Relationship between environmental variables and surface activity of scorpions in the Arid Chaco ecoregion of Argentina. Invertebrate Biology 132:145-155.

Nime, M.F., F. Casanoves \& C.I. Mattoni. 2014. Scorpion diversity in two different habitats in the Arid Chaco, Argentina. Journal of Insect Conservation 18:373-384.

Ojanguren-Affilastro, A.A. 2005. Estudio monográfico de los escorpiones de la República Argentina. Revista Ibérica de Aracnología 11:75-241.

Orr, T.J. \& M. Zuk. 2013. Does delayed fertilization facilitate sperm competition in bats? Behavioral Ecology and Sociobiology 67:1903-1913.

Parker, G.A. 1970. Sperm competition and its evolutionary consequences in the insects. Biological Reviews 45:525-567.

Parker, G.A. 1982. Why are there so many tiny sperm - sperm competition and the maintenance of 2 sexes. Journal of Theoretical Biology 96:281-294.

Parker, G.A. 2000. Sperm competition games between related males. Proceedings of The Royal Society B: Biological Sciences 267:10271032.

Parker, G.A. \& M.A. Ball. 2005. Sperm competition, mating rate and 
the evolution of testis and ejaculate sizes: a population model. Biological Letters 1:235-238.

Parker, G.A. \& T. Pizzari. 2010. Sperm competition and ejaculate economics. Biological Reviews 85:897-934.

Parker, G.A., M.A. Ball, P. Stockley \& M.J.G. Gage. 1997. Sperm competition games: a prospective analysis of risk assessment. Proceedings of the Royal Society B: Biological Sciences 264:17931802.

Peretti A.V. 1993. Estudio de la biología en escorpiones argentinos (Arachnida, Scorpiones): un enfoque etológico. PhD Thesis. UNC FCEFyN CDAI.

Peretti, A.V.1996. Una probable estrategia para inseminar más hembras en machos de Bothriurus bonariensis (Scorpiones, Bothriuridae). Journal of Arachnology 24:167-169.

Peretti, A.V. 2003. Functional morphology of spermatophores and female genitalia in bothriurid scorpions: genital courtship, coercion and other possible mechanisms. Journal of Zoology 261:135-153.

Peretti, A.V. 2010. An ancient indirect sex model: single and mixed patterns in the evolution of scorpion genitalia. Pp. 218-248. In The Evolution of Primary Sexual Characters in Animals (J. Leonard, A. Córdoba-Aguilar, eds.). Oxford University Press, New York.

Peretti, A.V. \& L.E. Acosta. 1998. Comparative analysis of mating in scorpions the post transfer stage. Zoologischer Anzeiger 237:259265.

Peretti, A.V. \& M. Battán-Horenstein. 2003. Comparative analysis of the male reproductive system in Bothriuridae scorpions: structures associated with the paraxial organs and the presence of sperm packages (Chelicerata, Scorpiones). Zoologischer Anzeiger 242:2131.

Pérez-Staples, D. \& M. Aluja. 2006. Sperm allocation and cost of mating in a tropical tephritid fruit fly. Journal of Insect Physiology 52:839-845.

Pizzari, T. \& G.A. Parker. 2009. Sperm competition and sperm phenotype. Pp. 207-245. In Sperm Biology: an Evolutionary Perspective (T.R. Birkhead, D.J. Hosken \& S.S. Pitnick, eds.). Academic Press, Oxford.

Polis, G.A. \& W.D. Sissom. 1990. Life history. Pp. 161-223. In The Biology of Scorpions (G.A. Polis, ed.). Stanford University Press.

R Core Team. 2016. R: A language and environment for statistical computing. R Foundation for Statistical Computing, Vienna, Austria. Online at https://www.R-project.org/

Ramm, S.A., G.A. Parker \& P. Stockley. 2005. Sperm competition and the evolution of male reproductive anatomy in rodents. Proceedings of the Royal Society of London B: Biological Sciences 272:949-955.

Rubolini, D., P. Galeotti, G. Ferrari, M. Spairani, F. Bernini \& M. Fasola. 2006. Sperm allocation in relation to male traits, female size, and copulation behaviour in freshwater crayfish species. Behavioral Ecology and Sociobiology 60:212-219.

Rubolini, D., P. Galeotti, F. Pupin, R. Sacchi, P.A. Nardi \& M. Fasola. 2007. Repeated matings and sperm depletion in the freshwater crayfish Austropotamobius italicus. Freshwater Biology 52:1898-1906

Sato, T., M. Shidate, T. Jinbo \& S. Goshima. 2006. Variation of sperm allocation with male size and recovery rate of sperm numbers in spiny king crab Paralithodes brevipes. Marine Ecology Progress Series 312:189-199.

Schärer, L. \& D.B. Vizoso. 2007. Phenotypic plasticity in sperm production rate: there's more to it than testis size. Evolutionary Ecology 21:295-306.

Schärer, L., P. Ladurner \& R.M. Rieger. 2004. Bigger testes do work more: experimental evidence that testis size reflects testicular cell proliferation activity in the marine invertebrate, the free-living flatworm Macrostomum sp. Behavioral Ecology and Sociobiology $56: 420-425$

Scharf, I., F. Peter \& O.Y. Martin. 2013. Reproductive trade-offs and direct costs for males in arthropods. Evolutionary Biology 40:169184.

Schindelin, J., C.T. Rueden, M.C. Hiner \& K.W. Eliceiri. 2015. The ImageJ ecosystem: An open platform for biomedical image analysis. Molecular reproduction and development 82 (7-8):518529.

Schneider, J.M. \& P. Michalik. 2011. One-shot genitalia are not an evolutionary dead end - Regained male polygamy in a sperm limited spider species. BMC Evolutionary Biology 11(197):1-8.

Shuker, D.M., N. Currie, T. Hoole \& E.R. Burdfield-Steel. 2015. The extent and costs of reproductive interference among four species of true bug. Population Ecology 57:321-331.

Simmons, L.W. 2014. Sperm competition. Pp 193-218. In The Evolution of Insect Mating Systems. (D.M. Shuker \& L.W. Simmons, eds.). Oxford University Press, USA.

Snow, L.S.E. \& M.C.B. Andrade. 2004. Pattern of sperm transfer in redback spiders: Implications for sperm competition and male sacrifice. Behavioral Ecology 15:785-792.

Svärd, L. \& C. Wiklund. 1989. Mass and production rate of ejaculates in relation to monandry/polyandry in butterflies. Behavioral Ecology and Sociobiology 24:395-402.

Swallow, J.G. \& G.S. Wilkinson. 2002. The long and short of sperm polymorphisms in insects. Biological Reviews 77:153-182.

Thornhill, R. \& J. Alcock. 1983. The Evolution of Insect Mating Systems. Harvard University Press.

Vachon, M. 1953. The biology of scorpions. Endeavour 12(46):80-89.

Vahed, K. 2006. Larger ejaculate volumes are associated with a lower degree of polyandry across bushcricket taxa. Proceedings of the Royal Society B: Biological Sciences 273:2387-2394.

Vahed, K. \& D.J. Parker. 2012. The evolution of large testes: sperm competition or male mating rate? Ethology 118:107-117.

Venables, W.N. \& B.D. Ripley. 2002. Modern Applied Statistics with S. Fourth Edition. Springer, New York.

Volschenk, E.S., C.I. Mattoni \& L. Prendini. 2008. Comparative anatomy of the mesosomal organs of scorpions (Chelicerata, Scorpiones), with implications for the phylogeny of the order. Zoological Journal of the Linnean Society 154:651-675.

Vrech, D.E. 2013. Patrones de producción espermática en escorpiones (Arachnida, Scorpiones): una aproximación comparada y experimental. PhD Dissertation, Facultad Ciencias Exactas, Físicas y Naturales. Universidad Nacional de Córdoba.

Vrech, D.E., A.V. Peretti \& C.I. Mattoni. 2011. Sperm package morphology in scorpions and its relation to phylogeny. Zoological Journal of the Linnean Society 161:463-483.

Vrech, D.E., P.A. Olivero, C.I. Mattoni \& A.V. Peretti. 2014. Testes mass, but not sperm length, increases with higher levels of polyandry in an ancient sex model. PLoS ONE 9(4).

Watanabe, M., C. Wiklund \& M. Bon'no. 1998. The effect of repeated matings on sperm numbers in successive ejaculates of the cabbage white butterfly Pieris rapae (Lepidoptera: Pieridae). Journal of Insect Behavior 11:559-570.

Wedell, N. 1993. Spermatophore size in bushcrickets: comparative evidence for nuptial gifts as a sperm protection device. Evolution 47:1203-1212

Wedell, N., M.J.G. Gage \& G.A. Parker. 2002. Sperm competition, male prudence and sperm limited females. Trends in Ecology and Evolution 17:313-320.

Wigby, S. \& T. Chapman. 2004. Sperm competition. Current Biology 14(3):R100-R103.

Xu, J. \& Q. Wang. 2010. Thiotepa, a reliable marker for sperm precedence measurement in a polyandrous moth. Journal of Insect Physiology 56:102-106.

Manuscript received 30 December 2016, revised 17 November 2017 